\title{
Crébillon hijo, precursor de los libertinajes literarios del siglo XVIII
}

\section{Crébillon Fils, Forefather of Eighteenth-century Libertine Fiction}

\author{
José Luis GóMEZ VELÁZQUEZ \\ Facultad de Filosofía y Letras \\ Universidad Nacional Autónoma de México
}

\begin{abstract}
Resumen
Este artículo analiza la evolución del libertinaje de costumbres en la Francia del siglo XVIII. Para realizar tal tarea es necesario ir más atrás y rastrear la fuente misma de las corrientes libertinas que llevaron a la tradición francesa a crear dicho género narrativo. Así pues, en la primera parte de la investigación se realiza una búsqueda por las fuentes de este género literario y las implicaciones filosóficas del mismo. En un segundo tiempo, se abordan autores propios del siglo XVIII, quienes a ojos de la crítica representan tres momentos importantes de este movimiento literario: Crébillon, Laclos y Sade. Por último, se analiza la producción de Crébillon hijo como fundador de un movimiento estético que es reinterpretado por varios autores.
\end{abstract}

Palabras clave: libertinaje, literatura libertina, Crébillon hijo, Laclos, Sade

\begin{abstract}
This article analyzes the evolution of libertine fiction during the 18th century in France. To do so, we need to locate the source of those libertinisms that create this narrative genre. In the first part of this study we focus on the sources of the literary movement and its philosophical implications. After that, it will be necessary to analyze the work of three eighteenth-century authors who represent the three moments of libertine fiction: Crébillon fils, Laclos, and Sade. Finally, it seems important to analyze the work of Crébillon fils as the founder of this aesthetic movement that is reinterpreted by several authors.
\end{abstract}

Keywords: libertinism, libertine fiction, Crébillon fils, Laclos, Sade 


\section{La fuente histórica del libertino}

Desde la Roma Antigua hasta nuestros días, el adjetivo "libertino" ha sido causa de polémica dentro de las sociedades en las que se ha empleado. Esta noción nos remite al placer, pero también al castigo y al dolor, pues autores como Sade y Laclos están anclados en el imaginario que envuelve a esta palabra. El "libertinaje" se instaura dentro de la producción literaria francesa desde el siglo XVII con el llamado libertinaje erudito, hasta llegar a nuestros días. Sin embargo, es el siglo XVIII el que habrá de darle a la palabra una carga semántica que se estableció dentro del pensamiento occidental gracias al rescate, durante el siglo XX, de muchos textos censurados de los siglos XVIII y XIX. Aún hoy podemos asistir a las reescrituras de dicho concepto bajo plumas como las del autor Jean Baptiste Del Amo, quien en 2008 publicó Une Éducation libertine bajo las ediciones Gallimard, novela ambientada en el París libertino del siglo XVIII. Mientras surgen nuevos personajes libertinos (pensemos en Gaspard en la obra de Del Amo), contemplamos también un gusto renovado por el libertinaje —o quizá debamos decir por los libertinajes del siglo XVIII-. Numerosas adaptaciones filmicas de obras como Les Liaisons dangereuses han sido llevadas a la pantalla en varios idiomas y en escenarios distintos unos de otros, desde el universo neoyorkino de los años 90 bajo la mirada de Roger Kumble con Cruel Intentions (1999), hasta el Shanhai de los años 30 bajo la dirección de Hur Jin-Ho, con su película Dangerous Liaisons (2012).

Bajo este esquema, María Tortajada (2015) habla incluso de una "constelación libertina". Este término explica acertadamente el gran número de acepciones que se pueden desprender de esta palabra, pues es casi imposible hablar de un solo y único libertinaje; se debe pensa más bien en los libertinajes. La propuesta de este trabajo intenta trazar la evolución de estos libertinajes. Se propone un estudio que encuentra en la producción de Crébillon hijo el referente de la producción libertina francesa del Siglo de las Luces. Para poder hacerlo, es necesario plantear las características de la figura del libertino. Aunque cada época ha utilizado la etiqueta de "libertino" para designar a alguien o algo que rompe de alguna manera con cierto orden preestablecido, para algunos autores es justamente lo contrario: un código estricto construido con la finalidad de conservar un orden social. No obstante, uno de los puntos recurrentes dentro de todos los libertinajes es la relación de poder y de libertad entre el sujeto libertino y la sociedad que lo acoge. Asimismo, el libertino ha cuestionado los preceptos morales, sociales, religiosos o filosóficos al reclamar de alguna manera su independencia al momento de actuar, y sobre todo la libertad de pensamiento en sus diferentes facetas, desde la filosófica hasta la sexual.

Hoy en día el llamado libertinage de mœurs ${ }^{1}$ del Siglo de las Luces se delimita con ciertos elementos que son cuestionados. Se concibe este movimiento como una corriente

\footnotetext{
${ }^{1}$ Movimiento literario de principios y mediados del siglo XVIII que se caracteriza por tejer tramas en torno a los procesos de seducción. El cuento y la novela libertina de este movimiento encuentran en Crébillon, Vivant Denon y Choderlos de Laclos a algunos de sus más grandes representantes.
} 
propiamente francesa, con referentes emblemáticos en el imaginario colectivo como el marqués de Sade o la Corte de Luis XVI. Lydia Vázquez (2015) se pregunta si este fenómeno es susceptible de traducción (pregunta para la que realizadores como Hur Jin-Ho y Roger Kumble seguramente tendrían una respuesta positiva de manera inmediata). Vázquez se replantea la validez del libertinaje francés del marqués de Sade en otros idiomas, otras latitudes y otros tiempos en su artículo "Le Libertinage est-il traduisible aujourd'hui? Le cas de Sade en espagnol”. De la misma forma, Stéphanie Genand (2015) se pregunta si "Le Libertinage existe-t-il au féminin?", llevando la discusión al terreno de los estudios de género, mientras que Michel Delon (2015c) explora la vigencia del movimiento dentro de la creación literaria contemporánea en la entrevista realizada a Jean Baptiste Del Amo intitulada "Libertinages d'hier et d'aujourd'hui".

Cabe destacar que estas reflexiones parten del libertinaje como lo concebimos en este trabajo - es decir, como el libertinage de mœeurs del siglo XVIII. Es necesario decir de igual manera que estos textos nos muestran la riqueza de una producción que puede aportar aún muchos elementos para el conocimiento en el campo de la investigación literaria de nuestros días; todos los textos que se acaban de mencionar fueron publicados en el número 50 de la Revue de la Bibliothèque Nationale de France en 2015. Y, si los textos estudiados tienen una fuente gala, parece ser que es de igual manera la crítica literaria francesa la que se preocupa por dicho género.

Autores como Jean-Claude Margolin reivindican al movimiento libertino como un fenómeno propiamente francés, o por lo menos de origen francés: "car l'expression et peut-être l'idée de libertin sont nées dans le pays de culture française" (Margolin, 1974: 1). Antoine Adam, por su parte, reconoce las diversas interpretaciones de la palabra, pero al igual que Margolin centra el fenómeno libertino dentro de un universo propiamente francés: "L'on sent là, très vivement, quelles réalités différentes couvre le mot de libertin, et l'on comprend qu'en fait l'usage l'applique à tous ceux qui, à un titre quelconque, ont ébranlé les traditions sur lesquelles reposait la société française" (Adam, 1986: 24). De esta forma, el libertinaje se concibe como una creación francesa que se desarrolló dentro de las fronteras del país que lo vio nacer. Sin embargo, es interesante recalcar que el origen de la palabra se remonta a latitudes diferentes. Para poder abordar de manera más precisa el libertinaje del Siglo de las Luces, comenzaremos por explicar las raíces del término y su evolución a través de la tradición literaria, pero de igual manera exploraremos su carácter histórico. Margolin trabaja de forma puntual la evolución de la palabra en su texto Libertins, Libertinismes et "libertinage" au XVIème siècle. Antes de pasar de lleno a las diferencias entre las épocas, señalemos que el libertino siempre ha sido objeto de cierto grado de reproche social a causa de su dimensión transgresora: "le libertin a toujours désigné un adversaire ou un homme auquel on reprochait sa manière d'être, de juger ou de sentir" (Margolin, 1974: 1).

El abanico de facetas libertinas que exploraremos comienza en la época clásica. En el contexto romano un hombre denominado "libertinus" era aquel que había vivido bajo el yugo de la esclavitud y que había obtenido la libertad —un affranchi en términos franceses-. Éste es el primer rastro del vocablo que nos plantea Margolin y bajo 
el cual habrán de tejerse las diferentes nociones de libertino a través de la historia: "Le libertin est un homme qui a été affranchi —ou qui s'est affranchi_ d'une condition servile, un homme qui a connu une situation personnelle de dépendance et qui jouit à présent de l'indépendance" (Margolin, 1974: 2). La búsqueda de la libertad, como ya hemos dicho, se presenta desde los albores del concepto de libertino. Lejos de crear una unión entre la sociedad que los sometió y los nuevos hombres libres, pareciera que se verá acentuada una separación entre estos dos elementos. Dicho de otra manera, los libertinos, aunque hombres libres, nunca podrán formar parte del sistema que los puso previamente en una situación de esclavitud o rechazo. Como bien señala Margolin, es difícil que los nuevos libertinos sean percibidos en el mismo nivel que aquellos que los rodean: "Les libertins étaient des hommes — ou des femmes - libres au second degré. Quelle société a-t-elle d'ailleurs jamais échappé à cette manière de voir et de sentir, quand il s'agissait pour elle de faire coexister les anciens maîtres et les anciens esclaves?" (Margolin, 1974: 3). Incluso personajes como Madame de Merteuil y el vizconde de Valmont vivirán a expensas de las reglas de una sociedad hipócrita que los juzgará por sus actos, perdiendo así todos los privilegios que pensaban tener:

Madame de Merteuil, en arrivant de la campagne, avant-hier jeudi, s'est fait descendre à la Comédie Italienne, où elle avait sa loge ; elle y était seule, et, ce qui dut lui paraître extraordinaire, aucun homme ne s'y présenta pendant tout le spectacle. À la sortie, elle entra, suivant son usage, au petit salon, qui était déjà rempli de monde ; sur le champ il s'éleva une rumeur, mais dont apparemment elle ne se crut pas l'objet. Elle aperçut une place vide sur l'une des banquettes, et elle alla s'y asseoir ; mais aussitôt toutes les femmes qui y étaient déjà, se levèrent comme de concert et l'y laissèrent absolument seule. Ce mouvement marqué d'indignation générale fut applaudi de tous les hommes, et fit redoubler les murmures, qui, dit-on, allèrent jusqu'aux huées. (Choderlos de Laclos, 1998: 452)

Este fragmento de Les Liaisons dangereuses ofrece un panorama bastante claro de cómo los libertinos del siglo XVIII comparten rasgos en común con los de la época clásica. Se saben pertenecientes a una sociedad, pero se desprenden de la misma para transformarse en seres satelitales que en muchos casos salen de la esfera social en la que se encontraban, como es el caso de Madame de Merteuil al final de la obra de Laclos.

Podemos encontrar ejemplos de libertinos en diversos momentos de la historia entre la época clásica y el siglo XVIII en Francia. Quizá uno de los ejemplos más conocidos lo tengamos en el siglo XVI, con el caso de Ronsard, quien en sus Odas alude a Horacio con el adjetivo "libertino" justamente para hacer una distinción entre sus orígenes y los del otro autor. De esta forma el poeta francés reivindica su nobleza en detrimento de los orígenes de Horacio, al ser éste hijo de un "libertino", es decir, de un esclavo liberado: "Horace harpeur Latin, Estant fils d'un Libertin, Basse et lente avoir l'audace [...]" (Ronsard, 1857: 103). Poco a poco la palabra dejará de tener esta connotación para comenzar a asociarse con la libertad de pensamiento y la llamada "libertad carnal". Bajo un clima de dominio religioso en todas las esferas de la vida social, 
era de esperarse que la palabra "libertino" fuera connotada negativamente, pues ésta presupone el alejamiento de los preceptos de la época. Ya desde el Renacimiento, Calvino establecía estas dos vertientes del libertinaje. Serán justamente estos dos tipos de libertinaje los que habrán de desarrollarse en los dos siglos por venir; por un lado el libertinaje erudito del siglo XVII, centrado en la libertad de pensamiento, y por otro lado el libertinaje de costumbres, eje de la creación dentro de la que se instauran autores como Crébillon, Denon y Laclos. "Calvin distingue deux groupes que la tradition entérinera et que l'on retrouvera parfois séparés, parfois mêlés dans les siècles suivants: les libertins d'esprits et les libertins de mœurs" (Margolin, 1974: 7). Resulta fundamental recalcar el matiz que Margolin da al planteamiento de Calvino, pues es cierto que no siempre se separarán estos libertinajes (el libertinaje creado por Sade, por ejemplo, conlleva una fuerte carga filosófica). En obras como Les Égarements du cœur et de l'esprit, de Crébillon, no se pueden dejar de lado las reflexiones en torno al amor. El libertinaje del siglo XVIII es, pues, el resultado de una serie de corrientes de pensamiento que no se pueden separar unas de otras. Todas ellas están ligadas a la noción de libertad y a la vez a una fuerte dimensión de marginalidad social, pues todos los libertinos son de alguna forma seres al margen de sus sociedades.

Ya entrado el siglo XVII, figuras como Pierre Gassendi y uno de sus discípulos, Cyrano de Bergerac, desarrollan un tipo de libertinaje de carácter filosófico con el cual la libertad de pensamiento se reivindica. Adam escribe acerca de Gassendi que su trabajo se centra en la "libertad íntima del pensamiento", siempre con un espíritu conciliador y que invita a la reflexión interna: “'il ne songeait pas à imposer, il ensegnait à penser"' (Adam, 1986: 15). Estas ideas serán retomadas y desarrolladas por sus seguidores y posteriormente por los libertinos del siglo XVIII. La libertad de pensamiento y los cuestionamientos que de ella se desprenden serán un tópico privilegiado por los escritores libertinos del Siglo de las Luces.

\section{Los libertinajes del siglo XVIII}

La producción de textos durante el siglo XVIII desvela un complejo engranaje que la crítica se ha dado a la tarea de estudiar. La novela libertina no podía ser la excepción. A juicio de María Tortajada (2015) podemos hablar de una producción polifónica, a ratos compleja de descifrar. Tortajada establece un eje estilístico que reagrupa a los textos libertinos bajo dos preceptos: "le discours voile" y una relación víctima-victimario ${ }^{2}$ entre los amantes:

Que ce soit dans la représentation d'une scène licencieuse ou dans un échange séducteur, que cela concerne le discours du narrateur ou celui du personnage, une 'gaze'

${ }^{2}$ Esta relación establecida por Tortajada se refiere al vínculo que el libertino establece con su amante: siempre uno de ellos va a ser engañado. 
vient recouvrir ce qui pourrait choquer. Toute parole est soumise au double registre, toute scène érotique est voilée. Dans ce libertinage, le jeu de séduction renvoie à la connivence autour d'un code partagé plus qu'à la tromperie. Bien sûr le libertinage déploie aussi les techniques d'une séduction trompeuse en quête de victimes. (Tortajada, 2015: 3)

La seducción es uno de los ejes que definen a la producción libertina del siglo XVIII. Habría que recalcar que, si bien el marqués de Sade escribe en el mismo siglo que Crébillon y Laclos, no podemos estudiarlo desde la misma óptica que a las novelas libertinas "gazées", ${ }^{3}$ pues en el corpus producido por este aristócrata las alusiones explícitas a los órganos sexuales y al acto sexual están ampliamente desarrolladas: no hay nada oculto. Esto corresponde a una estética que se separa de manera tajante de sus predecesores.

Si bien Sade se desprende de una tradición libertina, no es fácil agrupar de manera precisa la obra de los escritores que lo antecedieron. Podemos establecer elementos que circunscriben dichos textos a la llamada "literatura libertina de costumbres" o "libertinage de mœurs". Tortajada explicita dos conceptos bastante acertados. El primero de ellos sería el insinuar y nunca explicitar el acto sexual, poniendo un especial énfasis en el proceso de la erotización. El segundo tendría que ver con el establecimiento de las relaciones de poder entre los personajes. Otros aspectos han sido señalados como ejes unificadores de este corpus libertino. Resaltan de este modo el ambiente aristocrático que enmarca la diégesis, la posición de poder que ejerce la mujer libertina y el elemento filosófico. Uno más se dibuja en el espacio y los objetos que constituyen y construyen un universo erotizado propicio al amor, al engaño y a la seducción.

Jean François Perrin y Philip Stewart prestan especial atención a la discusión aquí aludida en su publicación del año 2004, Du Genre libertin au XVIIIème siècle. No es fortuito que hayan elegido abrir este estudio con una cita de Ah Quel conte! de Crébillon: "Je voudrais bien savoir de quel genre est un "certain genre" (Crébillon, 1755: 9). Como veremos a lo largo de esta exploración, Crébillon fue un pionero que estableció parámetros sólidos en materia narrativa y estilística que habrían de ser reinterpretadas por múltiples autores. La obra de este francés considerado como el "padre de la novela libertina" da pie a un debate sobre el género libertino en la obra dirigida por Stewart y Perrin, que recopila las inquietudes de una serie de investigadores en torno al tema, bajo el marco del coloquio internacional intitulado "La Littérature libertine au XVIII ème siècle: existe-t-il un genre libertin?", llevado a cabo en la Universidad de Grenoble en 2002. Quizá uno de los aspectos que saltan más a la vista dentro de esta discusión que se hilvana en torno al género libertino es el hecho de que este agrupa-

\footnotetext{
3 Entendemos textos "gazés" como aquéllos que dejan entrever al acto sexual bajo procedimientos estilísticos que sugieren, pero nunca explicitan: asistimos a un proceso en el que un velo se interpone entre la escena cruda y la imagen que se filtra entre velos y gasas.
} 
miento surge desde la crítica del siglo XX. La novela libertina, si es que podemos hablar de un género novelístico como tal (pues muchos de los textos en el siglo XVIII aparecían como obras panfletarias o como cuentos), engloba una serie de subgéneros que van desde las memorias y los textos epistolares, hasta los llamados cuentos galantes. Jean François Perrin dice acerca del corpus de textos estudiados en el marco del coloquio ya mencionado que "Certaines interventions en interrogèrent la diversité, voir l'hétérogénéité au plan typologique: conte, roman-liste, roman de formation, carrière de la prostituée, etc. ; à celui des genres apparentés: mémoires, théâtre, littérature épistolaire, etc. ; ainsi qu'à celui de l'intertextualité, notamment par rapport au dialogue pédagogique et/ou philosophique" (Perrin y Stewart, 2004: 9).

Como ya hemos explicado, la palabra "libertinaje" presupone una complejidad amplia que va más allá de un solo vocablo francés circunscrito al Siglo de las Luces. El corpus de textos que constituye este género es un constructo elaborado por la crítica literaria del siglo XX, como bien comenta Perrin, sin dejar de lado el carácter francés, poniendo a Crébillon en el centro de lo que hoy entendemos por Libertinage:

Mais si la notion de roman libertin stricto sensu, est une invention de la critique du XXème siècle, on peut distinguer dans la réception critique du XVIIIème siècle les éléments qui lui correspondent [...] En matière de périodisation, le plus large empan remonte vers l'Antiquité [...] et pousse vers la Restauration. Mais à l'intèrieur de ce cadre très vaste, les cadres temporels varient: Les Ragionamenti de l'Arétin sont très souvent donnés comme acte de naissance du récit libertin; mais Crébillon, celui des Égarements, celui du Sylphe, celui du Sopha revient souvent comme initiateur/créateur d'un genre nouveau consacré à l'amour. (Perrin, 2004: 10).

Lejos de elaborar un estudio exhaustivo de los múltiples subgéneros que puede encontrar el conjunto de textos libertinos, nos abocaremos a establecer líneas que nos permitan situar de manera clara el lugar en el que Crébillon escribe, y de forma breve la influencia y las rupturas que existen en textos posteriores con respecto a la obra de dicho autor. Podríamos trazar tres momentos dentro de la producción libertina. El que nos interesa sobre todo es el primero, aquél durante el cual Crébillon comienza a tejer referentes, el segundo con Laclos y Les Liaisons dangereuses, y el tercero con la producción del marqués de Sade.

Nuestra primera etapa abre con Crébillon hijo. Es importante precisar cuáles fueron los lineamientos que caracterizan al estilo de Crébillon. Se puede hablar en términos de "crébillonage" para aludir a este conjunto de elementos temáticos y estilísticos. Le Sopha (1742), de Crébillon, reúne una tradición libertina que se da a la tarea de demostrar el poder erótico del texto "gazé":

Le Sopha de Crébillon est un «classique » de la littérature libertine [...] ce romanconte constitue une véritable anthologie critique du genre, puisqu'on peut y trouver à la fois l'abrégé d'une tradition [...] mais aussi une quasi modélisation de six formes génériques caractéristiques du corpus : le conte oriental, le récit de métamorphose, la 
carrière de la prostituée, le récit des plaisirs, la carrière du séducteur et la satire sociale. (Perrin y Stewart, 2004:14).

El argumento que será retomado por múltiples autores, incluido Choderlos de Laclos, se había establecido ya en Les Égarements du cour et de l'esprit, de Crébillon. Un joven aristócrata se abre paso en el mundo, a través de las enseñanzas de un código libertino en donde el amor no es necesariamente uno de los ideales perseguidos. La seducción aparece como uno de los motores de la novela libertina de Crébillon. De esta forma en Les Égarements, el joven Meilcour constituye su camino gracias a las enseñanzas de Versac y de Mme. De Lursay. Bajo el manto del placer y del mundo de la aristocracia, los personajes de Crébillon establecen relaciones de poder y de manipulación. Meilcour entra al mundo para el que fue formado no sin antes tomar las enseñanzas de la mejor amiga de su madre, Mme. De Lursay, y de un libertino experimentado, Versac (argumento que sin duda alguna podemos reencontrar en el complejo mundo de Laclos donde un par de jóvenes se ven envueltos en las manipulaciones de la marquesa de Merteuil y el vizconde de Valmont).

Al analizar el desarrollo de la producción de los dos autores salta a la vista que tienen múltiples rasgos en común. Ya hemos mencionado el mundo aristocrático en el que se desenvuelven las tramas y los tópicos que se evocan; tendríamos pues que añadir que el papel de la mujer para ambos es un tema central dentro de los textos. Las mujeres son quienes llevan las riendas de la sociedad libertina y en quienes se deposita el conocimiento y la aprobación de los miembros de la misma. En Les Liaisons Dangereuses es notable que Mme. de Merteuil encarna a la villana y a la reivindicadora del género femenino al mismo tiempo. Ella es quien manipula el juego en el que poco a poco los personajes de la novela irán cayendo. La contraparte representada por Mme. de Tourvel y Mme de Rosemonde sigue estando encarnada en el aura del personaje femenino: "La place et l'importance des femmes dans Les Liaisons Dangereuses souligne à l'évidence, une intention qui prépare le Discours de 1783 et les traités de femmes et de leur éducation : cinq rôles de premier plan contre deux pour les hommes" (Versini, 1998: 127).

Es muy interesante retomar en este sentido el final de Les Égarements du cœeur et de l'esprit, pues es justamente ahí, con un final abierto, en donde concluye esta obra de Crébillon. Meilcour, después de debatirse entre las enseñanzas de Mme. de Lursay y su amor por la joven Hortense de Théville, acaba por caer bajo los encantos de la seducción libertina representados por la amiga de su madre, dejando de lado el amor sincero encarnado por Hortense. La iniciación sexual de Meilcour por parte de Mme. de Lursay marca la entrada al mundo libertino y a la puesta en práctica de las enseñanzas que ella misma pudo proveerle. No existe un juicio de valor a las costumbres libertinas que se plantean a lo largo del texto: ninguno de los personajes es castigado. Incluso se puede establecer cierto triunfo de los libertinos, pues el orden preestablecido no cambia. Si bien Hortense de Théville aparece como una contraparte al universo mundano representado por Versac y Mme. de Lursay, no existe una batalla real 
en donde alguno de los campos sufra pérdidas. Podríamos decir que estos personajes no se oponen como en el caso de Laclos: no asistimos a una batalla sino a un reflejo de una sociedad con códigos específicos — códigos que, si se siguen, llevan a una vida placentera y sin mayores peligros- - . No hay muertes, no hay sufrimiento más allá de una ilusión frustrada en el caso de Meilcour, y no tenemos rupturas en la escala de valores ni en el sistema moral que se maneja: "Le jour commençait à paraître [...] Grâces aux bienséances que Madame de Lursay observait sévèrement, elle me renvoya enfin, et je la quittai, en lui promettant, malgré mes remords, de la voir le lendemain de bonheur, très déterminé, de plus, à lui tenir parole" (Crébillon, 1985: 248).

Aunque varias de las obras de Crébillon proponen un castigo a las "malas costumbres", como es el caso de Le Sopha, donde el alma de Amanzéi es encerrada en un mueble por su mal comportamiento en vidas pasadas, es necesario notar que no hay un castigo categórico por parte de la voz narrativa. Entendemos castigo categórico en este contexto como un tormento o un estado en donde el personaje es la víctima de un sufrimiento notorio. En Le Sopha, Amanzéi parece disfrutar el viaje para liberar su alma: moviéndose de sopha en sopha, el alma de este cortesano goza con las escenas que se muestran ante él. Brahma resulta ser una deidad que inflige un castigo que da cabida al placer y, de cierta forma, a la felicidad a través de la seducción y del goce. El camino que recorre Amanzéi nos llevará por una serie de relatos en los que el personaje se deleita en más de una ocasión: "J'attendais avec impatience, ce que deviendrait la situation entre deux personnes si sages, s'étaient si imprudemment engagées" (Crébillon, 1995: 102).

La novela epistolar de Laclos Les Liaisons dangereuses surge como una ruptura con la tradición establecida por Crébillon y que varios autores como Vivant Denon continúan. Dicha coyuntura abre la segunda etapa del libertinaje. Laclos retoma múltiples elementos de la obra de Crébillon y de la tradición que éste comenzó a establecer. El gran punto de separación entre uno y otro es el final de las novelas y la condena categórica que Laclos inflige sobre los personajes libertinos. Tanto la marquesa de Merteuil como el vizconde de Valmont son fuertemente castigados por la conducta libertina que habían sostenido durante años — ella con la muerte social y la fealdad que se imprime sobre su rostro a causa de la viruela, y él con el sufrimiento amoroso y la muerte- L Laclos va más allá del castigo a los emblemas del libertinaje encarnados en estos dos aristócratas: todo su entorno se quiebra y sigue la misma suerte punitiva. Cécile de Volanges es encerrada en un convento que en términos espaciales representa el aislamiento y de nueva cuenta una muerte social. Mme. de Tourvel muere a manos del amor libertino, y tanto la madre de Cécile como Mme. de Rosemonde se limitan a ver horrorizadas el terrible desenlace. La carta que cierra el texto del militar expresa el profundo dolor de Mme. de Volanges sobre los acontecimientos, dejando claro que el camino para la felicidad y la paz no es de ninguna manera el camino de la filosofía libertina: 


\section{$32 \square$ CRÉBILLON HIJO, PRECURSOR DE LOS LIBERTINAJES LITERARIOS DEL SIGLO XVIII}

Quelle fatalité s'est donc répandue donc autour de moi depuis quelque temps, et m'a frappée dans les objets les plus chers ! Ma fille et mon amie! Qui pourrait ne pas frémir en songeant aux malheurs que peut causer une seule liaison dangereuse ? Et quelles peines ne s'éviteraient-on point en y réfléchissant davantage ! Quelle femme ne fuirait pas au premier propos d'un séducteur? Quelle mère pourrait, sans trembler, voir une autre personne qu'elle parle à sa fille ? (Choderlos de Laclos, 1998: 456)

Estratega y militar por formación, Laclos despliega todo un aparato bélico en la narración para dar cuenta de los peligros del mundo libertino que retrata y de los castigos que pueden desprenderse del mismo.

Delon (2000) plantea otra ruptura con la tradición crebilloniana. Se trata por supuesto del marqués de Sade. No podemos negar que el Marqués se instaura dentro de una tradición que reivindica el placer y el goce, al igual que lo habían hecho sus antecesores. Sin embargo, el sistema ético que se plantea dentro de la obra de Sade revoluciona de manera drástica las concepciones que tenemos sobre el corpus de textos llamados libertinos. En la obra de Sade ya no se deja absolutamente nada a la imaginación: los textos no son sugerentes; por el contrario, en ellos se detalla absolutamente todo lo que la tradición libertina había evitado. Esto constituye la última etapa del libertinaje. Mientras Crébillon hace de un cortesano un mueble, Laclos convierte a las personas en piezas de un juego, gracias a los cuales los libertinos van a poner en práctica sus estrategias. Sade convierte a los personajes en objetos, pero esta vez los objetos son desprovistos de humanidad: en muchas ocasiones aparecen como fetiches, sujetos al placer de otro personaje, sin que exista ningún escrúpulo causado por el sufrimiento.

Como una pequeña muestra cito un extracto de la tercera parte de las 120 Journées de Sodome: "Sa mère vend le pucelage du petit frère de Martaine à un autre homme qui n'encule que des garçons, et qui les veut à sept ans juste" (Sade, 1997: 275). Podemos constatar que el Marqués utiliza toda una serie de términos que no connotan, sino que denotan la acción sexual. Además, la alusión a la pederastia es un elemento violento que se contrapone de manera clara a toda la tradición libertina establecida por Crébillon y Laclos. Por último, el infante es representado como un objeto de compraventa; la idea resulta aún más perturbadora cuando conocemos la edad del niño, y que fue su propia madre la que lo vendió aun sabiendo la suerte a la que lo estaba condenando. De esta forma el personaje se convierte en un simple objeto subordinado al placer del comprador. Es claro que el libertinaje de Sade no corresponde a la misma estética que se había desarrollado a principios del siglo. Basta revisar casi cualquiera de las obras del Marqués para apreciar las diferencias entre el corpus creado por este aristócrata y la producción libertina de Crébillon y de Laclos. La Philosophie dans le boudoir (1795) o Les 120 Journées de Sodome (1785) dan muestra de un despliegue de características que establecen un código muy específico que difiere de la novela libertina en la que se circunscriben Le Sopha y Les Égarements du cour et de l'esprit. 
Así, podemos elucidar de manera breve las tres etapas del libertinaje que construyen desde nuestro punto de vista los tres grandes ejes de los libertinajes del siglo XVIII: el libertinaje crebilloniano, el libertinaje a la manera de Laclos y, finalmente, el libertinaje de Sade. Faltaría esclarecer de manera más puntual la importancia de Crébillon dentro de este corpus.

\section{Los libertinajes de Crébillon hijo}

Claude-Prosper Jolyot de Crébillon sentó las bases de un tipo de narrativa que tendría como eje la seducción y que inspiraría a autores posteriores en el Siglo de las Luces. Como ya se ha dicho, la importancia de estos escritores se refleja aún hoy en día en la creación literaria contemporánea. En la entrevista realizada por Michel Delon a Jean Baptiste Del Amo con motivo de su obra Une Éducation libertine, este último afirma que "Ce premier roman était pour moi un moyen d'utiliser une éducation littéraire classique, relativement tardive, pour mettre en mots un imaginaire, des obsessions. J'étais nourri par les auteurs du roman libertin, Sade, Laclos, Diderot, Crébillon, Rétif de la Bretonne [...] j'avais conçu, de ces lectures, une forme de nostalgie romanesque et fantasmée" (Delon, 2015c: 68).

Si bien lo que ahora nombramos libertinage está constituido por una amalgama compleja de textos y autores, es poco sensato dejar de reconocer la importancia y la inferencia de Crébillon en el imaginario francés del siglo XVIII y, como atestiguan autores como Del Amo, su vigencia en la tradición literaria francesa. Las formas y el abordaje de los temas libertinos pueden presentarse de diversas maneras; vale la pena desentrañarlos tanto para la crítica como para el público lector. Retomando de nueva cuenta las palabras del autor de Une Éducation libertine, "Le corps (et le désir), dernier bastion de l'intime et de la liberté, est sommé de se conformer à des normes esthétiques et morales édictées soit par les conservatismes, soit par les canons d'une beauté aseptisée. C'est ici que le recours á la subversion et la contestation de l'ordre de l'établi me semblent, en réaction, nécessaires" (Delon, 2015c: 69). Nos descubrimos herederos de esta tradición que reivindica el derecho al placer. Quizá de ahí la fama de Crébillon en la actualidad, pues esta prefiguración de mecanismos de placer se revela imprescindible. No obstante, la imagen del siglo XVIII, sobre todo del francés, continúa siendo aquella dominada por el pensamiento ilustrado. Castigado por la censura de finales de su siglo y por el recato de todo el siglo que le sobrevendría, nuestro autor es acusado de inmoralidad, "d'avoir peint les mœurs d'une époque et d'un société révolues, d'avoir fait l'apologie du libertinage" (Dornier, 1995: 5). Crébillon resurge desde el siglo XX como uno de los fundadores del movimiento libertino, definido por Michel Delon como "une floraison de l'imaginaire érotique, en continuité et parfois en contradiction avec l'affirmation de la pensée des Lumières" (2015a: 4).

Florence Lotterie (1995) establece que "le libertin se met toujours en scène dans la manœuvre consentie d'un récit de séduction qui a ses codes, ses règles, ses lois, néces- 
sairement suivies par des protagonistes plus ou moins conscients de leur rôle" (1995: 145). ${ }^{4}$ Aunque no fue particularmente prolífica, la obra de Crébillon nos ofrece por lo menos una decena de textos bajo los cuales podemos rastrear una estética y un establecimiento de los códigos del relato de seducción mencionado por Lotterie. El libertinaje, como todo sistema social y en este caso literario, conlleva una estricta configuración de lineamientos. Esto supone naturalmente la contribución de cierta tradición y una reinterpretación llevada a cabo por varios autores en diversos momentos. Laclos, Denon, Sade, e incluso Del Amo siglos después, se instauran de una u otra forma en la reinterpretación de este "arquetipo narrativo" del libertinaje mundano propuesto por Lotterie.

La producción literaria de Crébillon refleja una búsqueda formal al interior de la construcción de sus textos. Cada una de sus obras ofrece una experiencia seductora de lectura que demuestra un gran interés por explorar nuevos formatos narrativos. Vale la pena adentrarse brevemente en el conjunto de la obra de Crébillon para tratar de trazar los ejes principales del libertinaje propio de este autor y, de ser posible, establecer los diferentes momentos del libertinaje de costumbres del cual habría que sentar las bases. En su introducción a Les Mémoires d'un désenchanté, Carole Dornier coincide con Delon, poniendo a Crébillon en el centro de la creación literaria libertina del siglo XVIII, situándolo en una zona limítrofe que comparte con la Ilustración pero que se opone a las ideas que se gestaban en estos círculos filosóficos: "Romancier à succès avant 1750 , l'auteur du Sopha continue après cette date, à contre-courant du mouvement philosophique et de la nouvelle esthétique romanesque inspirée de Richardson, à représenter l'univers clos du libertinage aristocratique et à exprimer une « métaphysique du sentiment » opposé à la morale des « belles âmes »" (Dornier, 1995: 5). Y digo limítrofe porque, a pesar de su aparente desprendimiento de la corriente filosófica de la época y de establecer una estética centrada en la aristocracia, no podemos negar el gran contenido ético que conlleva la reivindicación del derecho al placer, la puesta en valor de la figura de la mujer y, en ocasiones, severas críticas a la hipocresía de la aristocracia, temas y guiños que le valdrán la simpatía de personajes como Voltaire y que suscitarán intercambios de ideas con otros tantos escritores como Diderot. ${ }^{5}$

La creación de Crébillon y los arquetipos que se desprenden de ella se encuentran dentro de una tradición teatral heredada de su padre dramaturgo, una influencia por la época impregnada de deseos de libertad y un universo aristócrata entregado al placer y a la seducción en su más amplio sentido. Dornier propone que la formación literaria de Crébillon habría comenzado en el mundo teatral al que pertenecía su padre, tanto

\footnotetext{
${ }^{4}$ Para un panorama más amplio sobre el género libertino véase "D’une loi du genre: les 'récits du séduction' ou le libertinage mondain comme archétype narratif”, de Florence Lotterie en Du genre libertin au XVIII siècle.

5 Para un acercamiento biográfico al autor véase la introducción de Carole Dornier a Les Mémoires d'un désenchanté, donde se rastrea el papel de Crébillon en el mundo intelectual francés del siglo XVIII, así como la elaboración y el contexto de publicación de su obra.
} 
como asistente a las representaciones, como escritor de versos para las representaciones. Dornier imagina al joven Claude Prosper paseando por los pasillos y los palcos que habrán de marcarlo a él y al arquetipo retomado por toda una generación de escritores. Así pues, nuestro joven autor "hante d'abord les coulisses des théâtre et aurait écrit ses premiers vers pour les parades de Théâtre Italien” (Dornier, 1995: 6). El elemento teatral se ve plasmado a lo largo de la obra narrativa del autor. La polifonía y la multiplicidad de focalizaciones dan muestra de ello. Este aspecto llevaría a un estudio mucho más minucioso, pues la dimensión teatral se refleja de igual forma en los desplazamientos de los personajes en espacios que parecerían construidos para una pieza teatral, y en los juegos de máscaras y espejismos que retoman la opacidad de un mundo del "paraître" que actúa en todo momento.

Justamente la obra de Crébillon se inaugura en 1730 de manera formal con un texto que se encuentra entre la forma teatral y la forma narrativa, un "conte dialogué". Le Sylphe, obra "bisagra" que le permite al autor abrir y cerrar su obra a dos géneros, explota por un lado las virtudes del mundo del teatro y por otro la narrativa con la forma cuentística. La seducción, tema que hechiza la producción de Crébillon, se cristaliza en la forma de un silfo que se manifiesta sonoramente ante una condesa. Atraída por las palabras de esta presencia mágica, la dama sucumbe al final del relato al discurso del libertino sin rostro. La presencia invisible es retomada en otro cuento centrado en el imaginario oriental de Las mil y una noches, Le Sopha, publicado en 1742, que se instaura dentro de este "libertinaje orientalizante" creado por Crébillon. Esta vez la voz narrativa se le otorga a la presencia invisible. El alma de Amanzéi castigada por Brahma es encerrada dentro de un mueble. El libertino en este caso se limita a narrar sus experiencias visuales sin posibilidad de interferir en las acciones de los que habitan el espacio diegético. Parecería a ratos que el narrador es un asistente a una puesta en escena sin incidencia dentro de la historia. El tema de la seducción dentro de un relato situado en el Oriente musulmán será retomado en Ah Quel Conte! que aparece en 1754. Así como en Le Sopha, en este cuento "politique et astronomique" un sultán, una sultana y un visir constituyen parte del primer destinatario de la historia; nosotros asistimos como lectores extradiegéticos a la narración en segundo plano.

La última obra que propongo incluir en esta categoría del libertinaje orientalizante es el primer gran éxito de Crébillon. Tanzaï et Néadarné, también conocida como L'Écumoire, de 1734, retoma una vez más la fuente oriental para tejer la intriga libertina. De nueva cuenta las presencias mágicas y enmascaradas se manifiestan. Una maldición compartida por una pareja de enamorados nos recuerda el castigo de Amanzéi impuesto por Brahma, sólo que esta vez la maldición es más bien física. El príncipe Tanzaï tendrá la desgracia de ver su pene convertido en un écumoire o espumadera de cocina. ${ }^{6}$ Este texto causará el encarcelamiento de Crébillon en la prisión

\footnotetext{
${ }^{6}$ La espumadera es un utensilio de cocina que se emplea para purificar caldos; usualmente está constituida por un mango y una pieza cóncava con orificios para dejar pasar el líquido y retener los sólidos.
} 
de Vincennes (muchos otros autores libertinos habrán de correr con la misma suerte por la publicación de sus obras; el caso más notorio tal vez sea el del marqués de Sade). Tanzaï et Néadarné resulta ser quizá la obra más polémica de la producción de Crébillon pues existe una condensación de temas contrarios a la moral de la época, tanto en la forma de la intriga como en el sustrato del texto: "il accumule thèmes et situations scabreux: impuissance, lubricité féminine, justification de l'infidélité" (Dornier, 1995: 7).

El segundo entramado libertino que el autor construye a lo largo de su carrera está hecho a base de intercambios por cartas. Esta suerte de "libertinaje epistolar" será el pilar de la estructura que Laclos retoma y complejiza para darle forma a Les Liaisons dangereuses. Ya desde su segunda obra publicada en 1732, Lettres de la Marquise de *** au Comte de $R^{* * *}$, Crébillon apuesta por el género epistolar para darle voz a sus personajes y le da a la carta un estatus central en la dinámica de la seducción. La batalla amorosa por medio de la palabra, y en este caso de la palabra escrita, retoma un esquema que Laclos rearticula en la relación de Tourvel y Valmont. Desde el momento en el que la persona seducida acepta emprender un diálogo con el libertino, aunque se resista, empieza a perder su autonomía y comienza a sucumbir a los encantos de la sensualidad y del engaño: "la règle qui veut qu'une femme qui accepte de lire des lettres d'amour et d'y répondre est déjà vaincue" (Dornier, 1995: 7). Años más tarde, en 1768, ya en la última parte de su producción, Crébillon publica Lettres de la Duchesse de *** au Duc de***. El poder femenino se hace presente y aunque es ella el objeto de la seducción, también es la figura de la dama la que manipula a su interlocutor. Les Lettres Athéniennes se circunscriben de igual manera dentro de este libertinaje epistolar. Obra inacabada que toma lugar en el Atenas del siglo V antes de Cristo, este texto cierra con la producción de Crébillon hacia 1771. Es interesante notar que, al final de su vida, Crébillon reivindica el género epistolar como garante del poder dialógico-amoroso sin dejar de lado la dimensión política que de estas relaciones se desprende; no por nada es justamente en la ciudad emblema de la filosofía y de la política donde toma lugar su última obra.

El tercer esquema que proponemos es un libertinaje constituido a base de diálogos. Este "libertinaje dialógico" centra la fuerza de la intriga en un intercambio oral dentro de la diégesis. Así pues, el camino de aprendizaje del joven Meilcour en Les Égarements du cour et de l'esprit se teje gracias a las conversaciones con Mme. de Lursay y con el libertino experimentado Versac. La publicación de Les Égarements se dio en dos etapas, pues obedece a su carácter de roman par tranches y a las normas de publicación impuestas por el gobierno francés entre la primera y la segunda parte de la obra, la primera con lugar en Francia en 1736 y la segunda y la tercera dos años después desde Holanda. La intriga de este texto se ve nutrida y complejizada en la novela epistolar de Laclos, donde una vez más una mujer de gran inteligencia y belleza mueve los hilos de la seducción, un libertino experimentado entra al juego y dos jóvenes aristócratas comienzan a conocer una sociedad libertina con reglas y códigos estrictamente 
establecidos. ${ }^{7}$ Las otras tres obras de Crébillon, Les Heureux Orphelins, de 1754, La Nuit et le Moment, dada a conocer en 1755, y Le Hasard du coin du feu, publicada en 1763, retoman en diferentes vertientes una experimentación formal desde la enunciación dialógica de los personajes. Las focalizaciones son multiplicadas, haciendo de la empresa de la seducción una tarea con múltiples aristas. Les Heureux Orphelins quizá se destaque de entre las tres como un ejercicio de reinterpretación valioso de ser mencionado. Esta obra se inspira en el texto de Eliza Haywood The Fortunate Foundlings y ofrece tres perspectivas de la figura del seductor libertino, siendo una de las más importantes Lord Chester. Parece ser que Crébillon ya cuestionaba una de las grandes preguntas de la crítica literaria sobre el siglo XVIII: el libertinaje parecería no ser sólo un fenómeno francés, sino una cierta pulsión seductora inherente al alma humana susceptible de gestarse en múltiples contextos espaciales. La Nuit et le moment y Le Hasard du coin du feu fijan la empresa de seducción gracias a diálogos que ocultan y desenmascaran las intenciones perversas de los libertinos, ambas en contextos espaciales privados y entre personajes pertenecientes a la aristocracia.

El talante narrativo de Crébillon se teje dentro de estos tres ejes. La separación que se propone en el presente estudio es solamente una propuesta de lectura que, lejos de querer fragmentar la producción de Crébillon, busca establecer lazos entre todas las obras y dar cuenta de la importancia de la producción libertina de Crébillon, tanto para el movimiento de la narrativa libertina del siglo XVIII, como para la historia literaria francesa. Esta serie de recursos se entremezcla en todas las obras y, si bien algunas toman lugar dentro de espacios imaginarios orientales, también apelan a una serie de figuras mágicas para construir sus intrigas; no se pueden cortar de la tradición libertina. El género epistolar, a su manera, también retoma presencias invisibles y se instaura dentro del diálogo. Esta producción se sostiene como un modelo libertino que le valdrá a Crébillon el título de "padre del libertinaje". La seducción por la palabra se encuentra en el centro de cada uno de estos textos. Ya sea en el Oriente heredero de Las mil y una noches o en el de la Atenas del siglo v a.C., las figuras libertinas entretejen juegos teatrales de máscaras que seducen tanto a la presa del libertino como al lector del siglo XVIII y al lector contemporáneo. De entre ellas, Le Sopha parece ser una de las más destacadas, pues en este microuniverso se teje quizá un retrato del movimiento libertino en su singularidad francesa y en su dimensión filosófica de la libertad del cuerpo y del espíritu.

El libertinaje se presenta así como un prisma de múltiples facetas que componen una producción digna de estudiarse hoy en día. Este movimiento que convive de cerca con la filosofía ilustrada se nutre de referentes que Crébillon desarrolló en los primeros años del siglo XVIII y que persisten hasta nuestros días en obras contemporáneas. Nuevas vetas de investigación surgen al preguntarnos cómo es que estos referentes son interpretados por los autores del siglo XXI.

${ }^{7}$ La estrecha relación entre Les Liaisons Dangereuses y Les Égarements du cœur et de l'esprit se ha analizado en un trabajo previo al presente estudio. Véase Gómez Velázquez (2014). 
$38 \square$ CRÉBILLON HIJO, PRECURSOR DE LOS LIBERTINAJES LITERARIOS DEL SIGLO XVIII

Bibliografía

AdAm, Antoine. (1986). Les Libertins au XVIIe Siècle. París: Buchet; Chastel.

AgUiRRe ORTA, Luis Alfonso (2006). Un acercamiento a la literatura libertina francesa sobre la vida conventual de los siglos XVI, XVII y XVIII. (Tesis de licenciatura, Universidad Nacional Autónoma de México). Recuperada de https://repositorio.unam.mx/.

CAzenobe, Colette. (1991). Le Système du Libertinage de Crébillon à Laclos. Oxford: The Voltaire Foundation.

CAZEnobe, Colette. (1997) Crébillon Fils ou La Politique dans le Boudoir. París: Honoré Champion Éditeur.

Citton, Yves. (2014). "Les Lumières de l'archéologie des media". Dix-Huitième siècle (46), 31-52.

Choderlos de Laclos, Pierre. (1998 [1782]). Les Liaisons Dangereuses. París: Pocket.

CréBILlon, Claude-Prosper. (1755). Ah Quel Conte!. Bruselas: Chez les frères Vasse.

CRÉBILlon, Claude-Prosper. (1984). Le Sopha (Jean Sgard, ed.). París: Desjonquères.

CRÉBILLON, Claude-Prosper. (1985). Les Égarements du Cour et de l'Esprit (Jean Dagen, ed.). París: Flammarion.

CréBILlon, Claude-Prosper. (1995). Le Sopha (Françoise Juranville, ed.). París: Flammarion.

CRÉBILlon, Claude-Prosper. (1996a). Le Sopha (Étiemble, ed.). París: Gallimard.

CRÉBILlon, Claude-Prosper. (1996b). Les Égarements du Cour et de l'Esprit (Étiemble, ed.). París: Gallimard.

CRÉBILlon, Claude-Prosper. (2010) Le Sopha (Catriona Steh, ed.). París: Éditions Garnier.

CRYle, Peter. (2003). La Crise du Plaisir 1740-1830. Aix-en-Provence: Presses Universitaires du Septentrion.

Darcos, Xavier; y TARTAYRE, Bernard. (1987). Le XVIIIè Siècle en Littérature. París: Hachette.

Delon, Michel. (2000). Le Savoir-vivre Libertin. Paris: Hachette.

Delon, Michel. (2011). Le Principe de Délicatesse: Libertinage et Mélancolie au XVIIIe Siècle. París: Albin Michel.

Delon, Michel. (2015a). "Introduction". Revue de la Bibliothèque Nationale de France (50), 3-5.

Delon, Michel. (2015b). “'J'abandonne mon esprit à tout son libertinage' De Diderot à Sade ou de la morale à l'esthétique". Revue de la Bibliothèque Nationale de France (50), 39-47. 
Delon, Michel. (2015c). "Libertinage d'hier et d'aujourd'hui. Entretien avec Jean Baptiste Del Amo". Revue de la Bibliothèque Nationale de France (50), 67-71.

Demoris, René, (2004). "Collection et oralité: De la réflexion sur la peinture au roman libertin". En Jean-François Perrin y Philip Stewart (comp.), Du Genre Libertin au XVIIIe siècle. París: Éditions Desjonquères. 113-122.

DORNIER, Carole (ed.). (1995). Les Mémoires d'un Désenchanté: Crébillon Fils, Les Égarements du cour et de l'esprit. Orléans: Paradigme.

ETIEMBLE. (1965). Romanciers du XVIIIè siècle. Bruges: Gallimard.

FranZINI, Elio. (2000). La estética del siglo XVIII (Campillo Francisco, Trad.). Madrid: Visor.

GENAND, Stéphanie. (2015). “Le Libertinage existe-t-il au féminin?”. Revue de la Bibliothèque Nationale de France (50), 15-19.

GÉRAUD, Violaine. (2005). "La Scénographie conversationnelle des contes de Crébillon" Féeries (2), p.161-173.

GolDZINK, Jean. (2005). À la Recherche du Libertinage. París: L'Harmattan.

Gómez VelázQuez, José Luis. (2014). Las caricias del libertinaje. Un acercamiento a la novela libertina. (Tesis de licenciatura, Universidad Nacional Autónoma de México). Recuperada de https://repositorio.unam.mx/.

HÉNAFF, Marcel. (1978). Sade: L'Invention du Corps Libertin. París: PUF; Croisées. HUERTA, Jorge. (2004). "Relaciones peligrosas o muerte por amor de un libertino". Litoral (34), 127-142.

LAFFONT, Robert. (1993). Romans Libertins du XVIIIè siècle. París: Bouquins.

LAFFOnt, Robert. (2001). Dictionnaire des Euvres Érotiques. París: Bouquins.

LAFON, Henri. (1995). "Les décors et les choses dans les romans de Crébillon". En Carole Dornier (comp.), Les Mémoires d'un Désenchanté: Crébillon Fils, Les Égarements du cour et de l'esprit Orléans: Paradigme. 133-145.

LASOWSKI, Patrick Wald. (1980). Libertines. Mayenne: Gallimard.

LOTTERIE, Florence. (1995). 'D'une loi du genre: les 'récits de séduction' ou le libertinage mondain comme archétype narratif". En Carole Dornier (ed.), Les Mémoires d'un Désenchanté: Crébillon Fils, Les Égarements du cœur et de l'esprit. Orléans: Paradigme.

MARGOLIN, Jean-Claude. (1974). Libertins, Libertinisme et "Libertinage" au XVIe siècle. París: Librairie Philosophique.

MARTIN, Christophe. (2004). Espace du féminin dans le roman français du XVIIIème siècle. Oxford. Voltaire Foundation.

Nagy, Peter. (1975). Libertinage et Révolution. París: Gallimard.

Perrin, Jean-François; y SteWART, Philip. (2004). Du Genre Libertin au XVIIIe siècle. París: Éditions Desjonquères.

Pimentel, Luz Aurora. (2010). El espacio en la ficción. Ciudad de México: Siglo XXI Editores. 
Pimentel, Luz Aurora. (2014). El relato en perspectiva. Ciudad de México: Siglo XXI Editores.

ReIChler, Claude. (1987). L’Âge Libertin. París: Editions de Minuit.

RonsARD, Pierre. (1857). CEuvres complètes. París: P. Jannet.

SADE, Donatien Alphonse François. (1997 [1785]). Les 120 Journées de Sodome. París: Flammarion.

SEBBAH, Alain. (2005). "Le mobilier libertin". Lumières, Esthétique et poétique de l'objet au XVIIIe siècle (5), 109-119.

SETH, Catriona. (2004). "Meubles-corps et corps-meubles". En Jean-François Perrin y Philip Stewart (comps.). Du Genre Libertin au XVIIIe siècle París: Éditions Desjonquère. 161-174.

SGARD, Jean. (2004). "Le Sopha comme classique du libertinage". En JeanFrançois Perrin y Philip Stewart (comps.) Du Genre Libertin au XVIIIe siècle. París: Éditions Desjonquères. 175-184.

TORTAJADA, María. (2015). "Rohmer libertin". Revue de la Bibliothèque Nationale de France (50). 59-67.

VÁZQUEZ, Lydia. (2015). “'Le libertinage est-il traduisible aujourd'hui?' Le cas de Sade en espagnol”. Revue de la Bibliothèque Nationale de France (50), 47-59.

VERSINI, Laurent. (1998). "Le Roman le plus intelligent” : Les Liaisons Dangereuses de Laclos. París: Honoré Champion Éditeur.

Wiegadant, Claude-Paule. (1995). Le Mobilier Français, Régence Louis XV. París: Éditions Massins. 